\title{
Sustainability assessment with time-series scores: a case study of Chinese provinces
}

\author{
Keishiro Hara $\cdot$ Michinori Uwasu · Helmut Yabar · \\ Haiyan Zhang
}

Received: 20 May 2008/Accepted: 17 December 2008/Published online: 7 February 2009

(C) Integrated Research System for Sustainability Science and Springer 2009

\begin{abstract}
Asian nations are currently facing a number of challenges, including environmental degradation and growing societal inequalities, in the course of their rapid economic growth and industrialization. Under such conditions, it is of critical importance to develop appropriate assessment tools with which to comprehensively measure the sustainability status of a region in order to guide its transformation into a sustainable society. This paper proposes a method of sustainability assessment consisting of the three components of environment, resource, and socioeconomic with aggregated time-series scores. This method can demonstrate the relative sustainability scores of targeted regions for different time periods, thereby, enabling the comparison of relative sustainability status for different regions over these periods. We carried out a case study of Chinese provinces for the years 2000 and 2005 using the proposed method and confirmed its applicability as the indicative type of sustainability assessment at the regional level, while actually investigating the sustainability status and its chronological changes. The results indicated that aggregate sustainability index scores improved between 2000 and 2005 in most provinces, mainly due to significant improvement in the scores for the socio-economic component, whereas the scores for the environment component deteriorated in some provinces over the study period. Our method proves to be effective in analyzing the relative sustainability status among targeted regions for different time periods in the form of aggregate scores, paving the
\end{abstract}

K. Hara $(\bowtie) \cdot$ M. Uwasu $\cdot$ H. Yabar $\cdot$ H. Zhang

Research Institute for Sustainability Science,

Osaka University, 2-1 Yamada-oka, Suita,

Osaka 565-0871, Japan

e-mail: hara@riss.osaka-u.ac.jp way for practical applications, such as policy analysis, in the pursuit of a sustainable society.

Keywords Sustainability assessment · Indicators · Integrated scores · Capitals · Kuznets curve · China

\section{Introduction}

One of the greatest challenges facing modern society is the realization of a sustainable society. Asian nations, including China, have been enjoying rapid economic growth over the last few decades, and this economic development has undoubtedly contributed to their overall affluence. However, economic growth now causes resource overconsumption due to inefficiency and environmental problems such as air pollution, pollution of water courses, and desertification (Feng and Yan 2007). In fact, environmental degradation and the incremental exploitation of natural resources are now pervasive and societal problems, such as the growing gap between rich and poor and urban and rural areas, have become very serious in nations with rapid economic growth. It is becoming a well-worn theme that economic growth at the macro level does not necessarily guarantee actual human well-being without securing the sustainability of society. It is critical to envision a sustainable society from a long-term perspective and guide modern nations in the right direction.

There have been numerous attempts to define the concept of 'sustainability' or 'sustainable development.' One of the most famous is that of the Brundtland Commission, formerly the World Commission on Environment and Development (WCED), which defined sustainable development as "development that meets the needs of the present without compromising the ability of future 
generations to meet their own needs" (WCED 1987). On the other hand, the International Union for the Conservation of Nature (1991) defines sustainable development as "improving the quality of life while living within the carrying capacity of supporting system." Along with the definitions of sustainability, a variety of sustainability assessment tools, such as indicators, have been also developed and applied to measure the actual sustainability status of societies. Each assessment tool has its own characteristic strengths and weaknesses and, thus, should be applied with specific assessment types and purposes in mind. It is indeed indispensable to adopt the most suitable assessment tools for investigating the sustainability status of regions from multilateral perspectives.

This paper begins by summarizing the recent debates over various sustainability assessment tools, including representative indicators, arguing the characteristics of these methods. Subsequently, an assessment method designed to estimate aggregate 'sustainability index scores' on the basis of three components, environment, resource, and socio-economic, each of which consists of a set of variables for measuring aspects of each component, is then proposed. A case study was conducted by applying the proposed method to measure the relative sustainability status of Chinese provinces based on statistical data from the years 2000 and 2005. Through this case study, we examined the applicability of the proposed method for the measurement of sustainability status at the regional level and clarified whether any provinces have been progressing from the viewpoint of sustainability over the study periods.

\section{Sustainability assessment and indicators}

Indicators at different scales

Sustainability indicators are one of the central tools of sustainability assessment (Ness et al. 2007). Indicators are important guidelines that assist in the development of strategies and actions, as they are capable of indicating the state, progress, or failures of measures undertaken for a specific system. They can help describe, diagnose, and clarify the problems of any system more accurately, and design and propose solutions to overcome such problems. Sustainability indicators are particularly aimed at measuring environmental improvement, social progress, and economic development. Most of such sustainability indicators are based on specific conditions for sustainable development. The well-known conditions for sustainable development are, perhaps, those included in the Natural Step, which identifies four principles considered to be essential environmental system conditions for the preservation of living systems
(Robert 2002). The principles for establishing a sustainable society require that:

1. Natural functions and diversity are not subject to systematically increasing concentrations of substances extracted from the Earth's crust.

2. Natural functions and diversity are not subject to systematically increasing concentrations of substances produced by society.

3. Natural functions and diversity must not be systematically impoverished by destructive forms of ecosystems degradation.

4. Human activities must be efficient enough to ensure that basic human needs are met equitably.

There are a wide variety of sustainability indicators currently in use, whose geographical targets vary from global/international scale to national and local/city level. The representative indicators for the national and global levels include, but are not limited to, the United Nations Commission on Sustainable Development (UNCSD) indicators, the environmental sustainability index (ESI), and the human development index (HDI).

The UNCSD Indicators for sustainable development is a set of 58 indicators with flexible adaptation at the national level. The indicator framework uses four dimensions (society, environment, economy, and institutions) and each dimension is further divided into themes, sub-themes, and indicators. For instance, one theme of the environmental dimension is the atmosphere, which is divided into three sub-themes: climate change, ozone layer depletion, and air quality. Each sub-theme has one or more indicators; in the case of climate change, for example, the indicator is greenhouse gas emissions (UNCSD 2001).

The ESI, developed at Columbia and Yale universities, is designed to utilize the following five components: environmental systems, environmental stresses, human vulnerability, social and institutional capability, and global stewardship. Each component has a group of so-called indicators (21 in total) and each indicator has a set of variables, for a total of 76 variables (Esty et al. 2005). The ESI is the equally weighted average of the 21 indicators and five components. For example, air quality is one of the indicators of the 'environmental systems' component. This indicator has four variables: NOx concentration, SOx concentration, particulate concentration, and indoor air quality. The ESI published its environmental sustainability rankings at the country level in 2001 and 2005.

The HDI considers three basic dimensions for human development: health, measured in terms of life expectancy at birth; education, measured in terms of adult literacy and primary, secondary, and tertiary enrolment; and, finally, standard of living, measured in terms of GDP per capita (UNDP 2006). As a basic indicator, the HDI ranks 
countries in terms of human development. Another important feature is that the HDI has been calculated on the yearly basis since 1975 . It should be stressed that indicators, such as ESI and HDI, are categorized as indicative assessment methods, aiming to analyze the relative status of sustainability or specific components of sustainability among targeted areas in the form of integrated scores, as opposed to the definitive type of assessment that attempts to argue the absolute status of sustainability, per se.

At the local level, it is worth mentioning the Sustainable Seattle initiative (1998). Community members consisting of local citizens selected 40 comprehensive indicators under five large categories of environment, population and resources, economy, youth and education, and health and community. Each individual indicator was analyzed over a period and interpretation of the assessment was made by investigating whether such indicators showed better performances over the period or not. What is striking about the initiative is that local citizens framed the assessment method and indicators, taking into account the relevancy to the local conditions and values of the community.

Along with sustainability indicators targeting the global, national, and local levels, the indicators can also be applied at the systemic level, for such systems as urban infrastructures. For example, several studies carried out sustainability assessment on urban water systems using a set of indicators (Butler and Parkinson 1997; Lundin et al. 1999; Mels et al. 1999; Hellström et al. 2000). It should be noted that the way in which a set of indicators are selected for application varies from one study to another, depending on the research scope, objectives, and system boundaries. It is also worth noting that most of the above studies tend to focus on the environmental sustainability of the targeted systems without specific reference to socio-economic aspects, suggesting that the quantitative analysis of societal aspects of a system in the context of sustainability is rather complicated.

Sustainability indicators could serve as useful guidelines for decision-making in the pursuit of a sustainable society. The Japanese government introduced the fundamental plan for establishing a sound material-cycle society in 2003 as its primary strategy for promoting the decoupling of economic growth from environmental pressure (Ministry of the Environment 2003). The plan set quantitative targets based on material flow analysis indicators. The targets, which focus on the upstream, circulation, and downstream stages of the Japanese material economy from the base year of 2000, must be achieved by 2010 in the following manner:

1. Input (upstream): $40 \%$ increase in resource productivity (GDP/direct material input), approximately from 280,000 to 390,000 yen/ton.
2. Circulation: $40 \%$ increase in recycling ratios (total recycled amount/direct material input), approximately from 10 to $14 \%$.

3. Output (downstream): $50 \%$ decrease in wastes going to final disposal sites, from 56 to 28 million tons/year.

These indicators are being monitored and evaluation of their performances has been conducted individually against such set targets.

The concept of resource productivity described in the above point 1 is also reflected upon in the process of the development of the third Basic Environmental Plan by the Japanese government. Representative indicators considered in the plan include: (1) $\mathrm{CO}_{2} / \mathrm{GDP}$, representing environmental efficiency or decoupling environmental loads from economic growth; (2) GDP/resource inputs, representing resource productivity; and (3) ecological footprint, which measures human demands on the biosphere in terms of the area of biologically productive land and sea required to provide the necessary resources and to absorb waste (WWF 2006).

With regard to the selection criteria for sustainability indicators, several guidelines have been proposed in previous studies. Hardi and Zdan (1997), for example, argue that the following criteria are important to meet in selecting indicators: (1) policy relevance; (2) simplicity; (3) validity; (4) availability of time-series data; (5) accurate and affordable data; (6) ability to aggregate information; (7) sensitivity to small changes; and (8) reliability. The selection of indicators should be carefully carried out, taking into account the characteristics and purpose of the assessment.

\section{Indicators based on the PSR approach}

The Organisation for Economic Co-operation and Development (OECD) published its core set of indicators for environmental performance reviews in 1993 (OECD 1993). This initiative was among the first to measure sustainability efforts, and continues to be widely used. The development of indicators was based on the pressure-state-response (PSR) framework, which was also used by the UNSCD for its sustainable development indicators. The PSR framework is based on the concept of causality, i.e., humans exert pressure on the environment and change its state, forcing different types of policy responses to overcome the situation (OECD 2003). According to this framework, there are pressure indicators that describe the variables affecting the environment, such as $\mathrm{CO}_{2}$ emissions, state indicators that address the state of the environment, such as the atmospheric concentrations of greenhouse gases (GHG), and response indicators that refer to the progress of the efforts or strategies for solving these problems. Although 
the first indicators were mostly focused on environmental issues, after the OECD conference on sustainable development indicators held in Rome in 1999, a list of core indicators, including social as well as environmental indicators (OECD 2000), was released. These social indicators focused on promoting self-sufficiency, health, equity, and social cohesion. Furthermore, in 2001, the OECD released a publication highlighting the importance of promoting human and social development and their relationship with economic development and well-being (OECD 2001).

Indicators based on the capital approach

Another way to classify sustainability indicators is based on the capital approach. As opposed to indicative indicator systems, such as the ESI, this approach aims to elucidate the sustainability level in a definitive manner, putting an emphasis on clarifying the concept of sustainability itself. The capital concept states that capital stocks provide a flow of goods and services necessary for human well-being (Ekins et al. 2008). According to this approach, there are basically four types of capital: natural capital, human-made capital, human capital, and social capital. Natural capital refers to the traditional natural resources, both renewable and non-renewable, as well as natural assets that are difficult to assign a monetary value. Human-made or manufactured capital is composed of physical or produced assets. Human capital represents the health, well-being and education, or potential productive capacity of humans as individuals. Finally, social capital addresses the values, norms, and trust embodied in institutions and social networks. The traditional approach in economics for capital tended to focus on the manufactured capital that was necessary to produce goods and services. However, this concept has been expanded to take into account the quality of labor (human capital), the strength of institutional structures that creates the social context for economic development (social capital), and the natural resources that provide the materials necessary for economic activities and the absorptive capacity to assimilate waste (natural capital).

In the capital approach, indicators basically fall into two groups: weak sustainability and strong sustainability indicators. The weak and strong sustainability concepts differ in their views on the substitutability of natural capital. The weak sustainability approach is based on the neo-classical view and advocates for a constant stock of capital where substitution of natural capital is possible. In other words, sustainability is possible as long as total capital stocks are maintained over time periods. Indicators under this group include the adjusted net saving (ANS), the genuine progress indicator (GPI), and 'green GDP.' The ANS was developed by the World Bank and estimates the wealth of nations based on the four types of capital mentioned previously, with the exception of human and social capital, which are expressed as 'intangible capital.' The ANS estimates the total wealth of nations in terms of the present value of future consumption, produced capital in monetary terms, and natural capital in terms of its shadow prices. Intangible capital is estimated as the difference between total wealth and natural and produced capital.

The strong sustainability approach advocates for a constant stock of each form of capital and puts restrictions on the substitutability of natural capital. The rationale is that non-declining natural capital is essential for socioeconomic development and must be maintained for future generations. This approach considers that nature provides several functions which are essential for human existence, such as climate stabilization and protection (e.g., the ozone layer), and waste and emissions-absorbing capacity. One of the main indicators under this group is, perhaps, the ecological footprint, defined as the area necessary to support human needs in terms of food, fiber, and materials, as well as the area necessary to absorb waste (Wackernagel and Rees 1996). The ecological footprint methodology gives an account of natural capital that can determine how much of nature's services are appropriated for supporting human activities without depleting the natural capital stock (Wackernagel et al. 2006).

This discussion could also be grouped with the potential for obtaining either or both ecological and economic sustainability. The advocates for ecological sustainability argue that there is poor or absent evaluation of natural capital, despite the fact that it is equally or more important to human survival and welfare than the other forms of capital (Ehrlich and Ehrlich 2008). In stressing the importance of natural capital, Daly (1991) stated that, in order to achieve sustainability, three conditions should be met:

1. The rates of use of renewable resources must not exceed their regeneration rates.

2. The rates of use of non-renewable resources must not exceed the rates of development of renewable substitutes.

3. The rates of pollution emissions must not exceed the assimilative capacity of the environment.

In an effort to highlight the importance of natural capital to the function of Earth's life support systems, Costanza et al. (1997), the World Bank (2006), and others have made great efforts to estimate the economic value of the world's ecosystem services and natural capital.

Based on the potential for obtaining either or both ecological and economic sustainability, four possible outcomes emerge. The first outcome would be that neither ecological nor socio-economic sustainability would be 
possible if production and consumption depend heavily on non-renewable resources, such as fossil fuels, or if the consumption of renewable resources is faster than its replenishment rate and no substitutes are available. In other words, this outcome fails to meet the conditions of sustainability argued by Daly (1991). A second outcome would be that socio-economic sustainability is possible but ecological sustainability is not. A typical example of this possibility is the availability of human-made substitutes of natural resources that could eventually lead to socio-economic sustainability, but at the cost of ecosystem loss. This outcome is basically advocated by the weak sustainability approach. A third outcome would be that ecological sustainability is possible, but socio-economic sustainability is not. An example of this outcome could occur if policies require industries to internalize their negative environmental externalities and those industries suffer huge economic losses. Finally, a fourth outcome is both socio-economic and ecological sustainability. This scenario would be feasible if, for example, both renewable and non-renewable resources are used with high efficiency, while alternative substitutes are continually promoted. Production and consumption patterns that respect the carrying capacity of the ecological systems would also be required.

\section{Case study of China}

\section{Assessment framework}

We conducted a case study by applying a novel assessment method to comprehensively analyze the relative status of sustainability for 31 regions of all of the Chinese provinces, autonomous regions, and municipalities (hereinafter, we call the targeted regions 'provinces'), with particular reference to the ESI approach, which we briefly explained in "Sustainability assessment and indicators". The basic framework of ESI was modified in this study to make the assessment system more flexible, allowing the comparison of the relative sustainability status of targeted regions for not just one, but various time periods.

Esty et al. (2005) reported the relative environmental sustainability performance of various countries for the year 2005. The ESI, as opposed to those with definitive types of indicators, such as the capital approach, is an indicative method that aims to clarify the relative sustainability performance between countries. Since the assessment method demonstrates sustainability status in the form of aggregate scores, it has the potential advantage of providing a clear message regarding overall pictures about relative sustainability status across targeted countries and is, therefore, considered to be useful for policy evaluations.
In Esty et al. (2005), the scores of ESI were calculated from aggregate component scores, representing important fields for assessing environmental sustainability. The ESI consists of five components, environmental systems, reducing environmental stresses, reducing human vulnerability, social and institutional capacity, and global stewardship. These five components are calculated from the aggregation of another 21 indicators and 76 variables, as shown in "Indicators based on the capital approach". These indicators represent more specific factors, such as water stress and eco-efficiency, and variables are directly obtained from real data.

The novel aspect of the case study with our method is the calculation of the relative performance of the sustainability status of China's provinces over two different time periods. More specifically, we developed the calculation framework so that the performance in terms of relative sustainability is comparable across provinces for different time periods, i.e., the years 2000 and 2005, on the same basis. With the indicative assessment method, we intend to explore the relative status of sustainability among provinces and simultaneously investigate chronological trends of such integrated sustainability status, components, and individual variables in each province.

\section{Selection of components and variables}

To evaluate China's sustainability at the provincial level, we first identified three components of sustainability. The selection of the criteria encompassed the current situation in China, i.e., the most important challenges that China is and will be facing. Rapid economic growth has not only caused huge disparities in socio-economic performance across regions, but also serious environmental issues. Further, with a population of 1.3 billion, efficient resource utilization has been, and will continue to be, one of the most critical issues in China. Based on these assumptions, we selected the following three components: environment, resource, and socio-economic, to address the sustainability status. Note that the second component, 'resource,' indicates the status of efficient resource usage.

With the significance and data availability in mind, we selected 22 variables from the China Statistical Yearbook from the years 2000 through 2006 (National Bureau of Statistics 2000-2006) to calculate the scores of three components for each province for the two time periods. Table 1 lists all of the variables constituting the three components. The socio-economic component, representing the quality of life and basic human needs, consisted of seven types of variables, including those related to basic human needs, such as water access. In particular, we included 'income gap' as a variable under the component to address the problem facing the rapidly growing nation. 
Table 1 Components and variables explanation

\begin{tabular}{|c|c|c|c|c|}
\hline Component & Type & Variable name & zVariable definition & Year \\
\hline Socio-economic & Quality of life & GRP/capita ${ }^{a}$ & $\begin{array}{l}\text { Gross regional product (GRP) per } \\
\text { capita }\end{array}$ & 2000 and 2005 \\
\hline Socio-economic & Quality of life & Income gap & $\begin{array}{l}\text { Ratio between per capita } \\
\text { consumption of urban and rural } \\
\text { households }\end{array}$ & 2000 and 2005 \\
\hline Socio-economic & Quality of life & Floor space/capita & $\begin{array}{l}\text { Total floor space of residential } \\
\text { building per capita }\end{array}$ & 2000 and 2005 \\
\hline Socio-economic & Basic human needs & Water access ${ }^{\mathrm{b}}$ & $\begin{array}{l}\text { Percentage of population with } \\
\text { access to tap water }\end{array}$ & 2004 and 2005 \\
\hline Socio-economic & Basic human needs & Gas access ${ }^{\mathrm{b}}$ & $\begin{array}{l}\text { Percentage of population with } \\
\text { access to gas }\end{array}$ & 2004 and 2006 \\
\hline Socio-economic & Basic human needs & Life expectancy & Life expectancy at birth & 1990 and 2000 \\
\hline Socio-economic & Basic human needs & Illiteracy & $\begin{array}{l}\text { Percentage of illiterate and semi- } \\
\text { literate among population over } \\
15 \text { years old }\end{array}$ & $\begin{array}{c}1994-1998 \text { and } \\
1999-2003\end{array}$ \\
\hline Environment & Green space & Forests coverage & Forest coverage area & $\begin{array}{c}1994-1998 \text { and } \\
1999-2003\end{array}$ \\
\hline Environment & Water & COD discharge & $\begin{array}{l}\text { Discharge quantity of chemical } \\
\text { oxygen demand (COD) in urban } \\
\text { domestic sewage }\end{array}$ & 2000 and 2004 \\
\hline Environment & Water & Sewage treatment ratio & $\begin{array}{l}\text { Treatment rate of urban domestic } \\
\text { sewage }\end{array}$ & 2000 and 2005 \\
\hline Environment & Water & Wastewater discharge/GRP & $\begin{array}{l}\text { Total discharge amount of } \\
\text { wastewater/GRP }\end{array}$ & 2000 and 2005 \\
\hline Environment & Air & Gas emission/GRP & $\begin{array}{l}\text { Total volume of industrial waste } \\
\text { gas emission/GRP }\end{array}$ & 2000 and 2005 \\
\hline Environment & Air & SOx emission/GRP & $\begin{array}{l}\text { Total emission of sulfur dioxide/ } \\
\text { GRP }\end{array}$ & 2000 and 2005 \\
\hline Environment & Waste & Solid waste discharge/GRP & $\begin{array}{l}\text { Discharge amount of industrial } \\
\text { solid wastes/GRP }\end{array}$ & 2000 and 2005 \\
\hline Environment & Waste & Solid waste treatment ratio & $\begin{array}{l}\text { Treatment rate of industrial solid } \\
\text { wastes }\end{array}$ & 2000 and 2004 \\
\hline Environment & Soil/water & Fertilizer usage & Consumption of chemical fertilizer & 2000 and 2005 \\
\hline Resource & Energy & Coal use/GRP & Consumption of coal/GRP & 2000 and 2004 \\
\hline Resource & Energy & Fuel oil use/GRP & Consumption of fuel oil/GRP & 2000 and 2004 \\
\hline Resource & Waste/material & Solid waste utilization & $\begin{array}{l}\text { Utilization rate of industrial solid } \\
\text { wastes }\end{array}$ & 2000 and 2004 \\
\hline Resource & Water & Water supply/GRP & $\begin{array}{l}\text { Volume of water supply for } \\
\text { productive use/GRP }\end{array}$ & 2000 and 2005 \\
\hline Resource & Water & Water availability/capita & $\begin{array}{l}\text { Total amount of available water } \\
\text { resources/capita }\end{array}$ & 2003 and 2005 \\
\hline Resource & Water & Industrial water use/GRP & Industrial water consumption/GRP & 2000 and 2004 \\
\hline
\end{tabular}

All data were obtained from the China Statistical Yearbook (National Bureau of Statistics 2000-2006)

a GRP per capita is calculated at a constant price for 2005

${ }^{\mathrm{b}}$ Each variable for 2000 was estimated using a regression method with original data from 2004 and 2005

The environment component, representing the environmental loads associated with economic activities, had nine variables, ranging from green space to air pollution, water pollution, and wastes. The resource component represents the efficient use and availability of natural resources. The variables included energy, material and water resource usages per unit (i.e., water use per gross regional product [GRP]), and availability. After setting the components and obtaining the data sets, the variables, component scores, and sustainability index scores were calculated using the 
procedure outlined in "Calculation procedures". Note that data for the Chinese provinces analyzed in the present study were directly excerpted from various editions of the China Statistical Yearbook, as stated in the footnote of Table 1.

\section{Calculation procedures}

After obtaining the data sets for the variables of all provinces, the calculation was made in the following manner.

\section{Step 1: normality test}

The sustainability index and components scores were calculated by aggregation. However, the aggregation procedure requires that all variables follow a normal distribution. Thus, we first conducted the skewness-kurtosis test to see if each variable followed a normal distribution. When the normality test failed (at the 0.05 significance level), the variable was transformed by taking a logarithm or exponential. All variables were transformed by either a natural logarithm or a squared-root.

\section{Step 2: z-score calculation}

We calculated a set of transformed variables in Step 1; however, these variables have different average and variance, which does not allow us to aggregate them. We, thus, computed a $z$-score for each variable to control for differences in the absolute values and variances across variables using:

$z_{i_{t}}^{j_{m}}=\frac{\mu^{j_{m}}-X_{i_{t}}^{j_{m}}}{\sigma^{j_{m}}}$

where $i_{t}$ denotes a province in year $t, j_{m}$ denotes a variable name within a component $m \in M=$ (environment, socioeconomic, resource), $X$ is a normalized variable, as described in Step 1, and $\mu$ and $\sigma$ are the mean and variance of the transformed variable, respectively. Note that the final sustainability index score is calculated such that the higher the score, the better the evaluation of provinces. Thus, the $z$-scores are calculated in the same manner, i.e., if the value of a variable has a higher property, such as GRP per capita, we used the following instead:

$z_{i_{t}}^{j_{m}}=\frac{X_{i_{t}}^{j_{m}}-\mu^{j_{m}}}{\sigma^{j_{m}}}$

Step 3: z-score aggregation

After obtaining $z$-scores for all provinces and variables for the two time periods, we aggregated the $z$-scores over the variables within one component using:
$I_{i_{t}}^{m}=\sum_{j_{m}} w^{m} z_{i_{t}}^{j_{m}}$

where $w^{m}$ denotes a weight for each variable in component $m$. We adopted equal weight for each variable in the three components in this study as the first step. This equal weighting is applied in the ESI framework as well. For example, the environment component consisted of nine variables; thus, the weight used for the aggregation was 1/9. A few provinces, such as Chongqing, lacked data on specific variables. In such cases, the value of a component was calculated by the average of the available variables, with the weights being equal. Thus, if eight variables were available, the weight for the aggregation would be $1 / 8$.

\section{Step 4: calculation of sustainability index scores}

The final sustainability index score for province $i$ is the mean (again, the equally weighted average) of the three components. That is:

$S I_{i_{t}}=\frac{\sum_{m \in M} I_{i_{t}}^{m}}{3}$

with the component weight, $w$, as $1 / 3$ for all components.

\section{Results and discussion}

Table 2 lists the calculated sustainability index scores for all of the examined provinces in 2000 and 2005. Table 3 shows the ranking of provinces based on the sustainability index scores for the combined results of 2000 and 2005; the results indicate that Beijing in 2005 had the highest sustainability score, followed by Beijing in 2000. Table 4 lists the results of the calculated scores by component (see the Appendix for the actual $z$-scores of the resource component as an example) and the changes in scores between 2000 and 2005 for each component, as well as the sustainability index, are shown in Figs. 1, 2, 3, 4, 5, 6, 7 and 8, in the form of a geographic information system (GIS). From Table 2, it is implied that, in most of the provinces, the scores of sustainability index improved in 2005 compared with performances in 2000 . The results in Table 3 identifies a general tendency that, under the method used in this study, municipalities such as Beijing, Shanghai, and Tianjin, most of which are considered as economically developed regions and, therefore, relatively affluent, are ranked high. This is mainly attributed to the fact that the scores of the socio-economic component appeared to be much higher in these municipalities in comparison with other provinces. In the present method, the weight of the three components is equal (1/3), and high scores of socioeconomic components, therefore, have considerable influence on the final sustainability index scores. 
Table 2 Sustainability index: scores in 2000 and 2005

\begin{tabular}{|c|c|c|}
\hline & 2000 & 2005 \\
\hline Beijing & 0.79 & 0.85 \\
\hline Tianjin & 0.73 & 0.76 \\
\hline Hebei & 0.40 & 0.50 \\
\hline Shanxi & 0.29 & 0.39 \\
\hline Inner Mongolia & 0.39 & 0.37 \\
\hline Liaoning & 0.43 & 0.52 \\
\hline Jilin & 0.47 & 0.52 \\
\hline Heilongjiang & 0.48 & 0.60 \\
\hline Shanghai & 0.68 & 0.74 \\
\hline Jiangsu & 0.48 & 0.57 \\
\hline Zhejiang & 0.63 & 0.70 \\
\hline Anhui & 0.38 & 0.47 \\
\hline Fujian & 0.59 & 0.71 \\
\hline Jiangxi & 0.35 & 0.49 \\
\hline Shandong & 0.42 & 0.49 \\
\hline Henan & 0.38 & 0.45 \\
\hline Hubei & 0.37 & 0.45 \\
\hline Hunan & 0.41 & 0.51 \\
\hline Guangdong & 0.54 & 0.61 \\
\hline Guangxi & 0.38 & 0.47 \\
\hline Hainan & 0.68 & 0.75 \\
\hline Chongqing & 0.44 & 0.54 \\
\hline Sichuan & 0.36 & 0.53 \\
\hline Guizhou & 0.24 & 0.31 \\
\hline Yunnan & 0.45 & 0.48 \\
\hline Tibet & 0.60 & 0.63 \\
\hline Shaanxi & 0.40 & 0.52 \\
\hline Gansu & 0.28 & 0.36 \\
\hline Qinghai & 0.47 & 0.43 \\
\hline Ningxia & 0.39 & 0.40 \\
\hline Xinjiang & 0.42 & 0.54 \\
\hline
\end{tabular}

Although socio-economic component scores, as a whole, improved in 2005, a detailed analysis of individual variables reveals different perspectives. For example, in 2005, the $z$-score for income gaps deteriorated in 17 provinces, i.e., more than half of the examined provinces, indicating that GDP growth alone does not guarantee the sustainability of a society. We stress that the examination of individual scores of variables and components are simultaneously needed to fully elucidate the sustainability status of a society, while the aggregate index score is very useful in grasping overall pictures of the relative sustainability.

It is also worth mentioning that the scores of the environment component decreased in some provinces over the study period. Figures 1 and 2 suggest that environmental conditions had worsened, particularly in the western and northeastern areas of China, between 2000 and 2005. Furthermore, some provinces around large municipalities showed decreased values of scores for the environment component; provinces around Beijing, for example, fell into the lowest category of scores, ranging between 0.0 and 0.21 . At this point, it is unclear whether environmental problems had been transferred from the municipalities to their surrounding provinces, and this issue awaits clarification by future and detailed studies.

Figure 9, which displays the calculated scores of all provinces in 2000 and 2005 shown in Table 4, elucidates the relationship between the scores of the socio-economic and environment components for all of the examined provinces. It indicates that there is a likely Kuznets curve correlation between socio-economic and environmental conditions, and this correlation was found to be statistically significant. Further, Hainan Province attained an outstanding positive score in terms of the relationship environment versus socio-economic component scores, at a time when other provinces tend to show low environmental performance in the middle of economic development (Fig. 9). Hainan is unique in that it is an island with a total area of $33,900 \mathrm{~km}^{2}$ and social conditions such as industrial structure and natural environment may be different from other provinces. However, it is significant that the assessment results clarifying the relative performance of sustainability and decomposed components across provinces could be used as basic information to further investigate the mechanisms and reasons for such high performances, or, in the opposite case, of poor performances.

In terms of national environmental policy, the Chinese government has tried to integrate environmental concerns into its development policy, and policy orientation has shifted to involve sustainable development. In fact, the government has set nationwide goals to control ambient pollution by targeting 12 major pollutants from three categories of air pollutants, water pollutants, and solid waste in the ninth five-year Plan (9th FYP: 1996-2000) (Dudek et al. 2001). The tenth FYP (2001-2005) integrated environmental protection with economic development, and stated that local governments undertake the major responsibilities of environmental conservation (State Environmental Protection Administration [SEPA] 2001). The 11th FYP (2006-2010) takes a more proactive approach and stresses the importance of improving living standards, setting long-term strategic policies for environmental protection and the sustainable use of natural resources (Yabar et al. 2009).

Figure 10 also implies a possible Kuznets curve correlation between socio-economic conditions and efficient resource utilization. However, if two exceptional cases, representing an exceptionally high performance in terms of efficient resources utilization at a low socio-economic 
Table 3 Sustainability index: scores and ranking (2000 and 2005 combined)
The number in parentheses indicates the examined year (2000 or 2005)

\begin{tabular}{|c|c|c|c|c|c|}
\hline Ranking & Provinces & Sus. index & Ranking & Provinces & Sus. index \\
\hline 1 & Beijing (05) & 0.85 & 32 & Guangxi (05) & 0.47 \\
\hline 2 & Beijing (00) & 0.79 & 33 & Jilin (00) & 0.47 \\
\hline 3 & Tianjin (05) & 0.76 & 34 & Anhui (05) & 0.47 \\
\hline 4 & Hainan (05) & 0.75 & 35 & Qinghai (00) & 0.47 \\
\hline 5 & Shanghai (05) & 0.74 & 36 & Henan (05) & 0.45 \\
\hline 6 & Tianjin (00) & 0.73 & 37 & Hubei (05) & 0.45 \\
\hline 7 & Fujian (05) & 0.71 & 38 & Yunnan (00) & 0.45 \\
\hline 8 & Zhejiang (05) & 0.70 & 39 & Chongqing (00) & 0.44 \\
\hline 9 & Shanghai (00) & 0.68 & 40 & Qinghai (05) & 0.43 \\
\hline 10 & Hainan $(00)$ & 0.68 & 41 & Liaoning (00) & 0.43 \\
\hline 11 & Zhejiang (00) & 0.63 & 42 & Xinjiang (00) & 0.42 \\
\hline 12 & Tibet (05) & 0.63 & 43 & Shandong (00) & 0.42 \\
\hline 13 & Guangdong (05) & 0.61 & 44 & Hunan (00) & 0.41 \\
\hline 14 & Heilongjiang (05) & 0.60 & 45 & Ningxia (05) & 0.40 \\
\hline 15 & Tibet (00) & 0.60 & 46 & Shaanxi (00) & 0.40 \\
\hline 16 & Fujian (00) & 0.59 & 47 & Hebei (00) & 0.40 \\
\hline 17 & Jiangsu (05) & 0.57 & 48 & Ningxia (00) & 0.39 \\
\hline 18 & Guangdong (00) & 0.54 & 49 & Inner Mongolia (00) & 0.39 \\
\hline 19 & Xinjiang (05) & 0.54 & 50 & Shanxi (05) & 0.39 \\
\hline 20 & Chongqing (05) & 0.54 & 51 & Guangxi (00) & 0.38 \\
\hline 21 & Sichuan (05) & 0.53 & 52 & Henan $(00)$ & 0.38 \\
\hline 22 & Shaanxi (05) & 0.52 & 53 & Anhui (00) & 0.38 \\
\hline 23 & Jilin (05) & 0.52 & 54 & Inner Mongolia (05) & 0.37 \\
\hline 24 & Liaoning (05) & 0.52 & 55 & Hubei (00) & 0.37 \\
\hline 25 & Hunan (05) & 0.51 & 56 & Gansu (05) & 0.36 \\
\hline 26 & Hebei (05) & 0.50 & 57 & Sichuan (00) & 0.36 \\
\hline 27 & Jiangxi (05) & 0.49 & 58 & Jiangxi (00) & 0.35 \\
\hline 28 & Shandong (05) & 0.49 & 59 & Guizhou (05) & 0.31 \\
\hline 29 & Heilongjiang (00) & 0.48 & 60 & Shanxi (00) & 0.29 \\
\hline 30 & Jiangsu (00) & 0.48 & 61 & Gansu (00) & 0.28 \\
\hline 31 & Yunnan (05) & 0.48 & 62 & Guizhou (00) & 0.24 \\
\hline
\end{tabular}

stage, i.e., Tibet in 2000 and 2005, are excluded from the analysis, then the trend of the correlation is not observed. In fact, the relationship would become a one-to-one correspondence, rather than a Kuznets curve. This one-to-one correspondence would be reasonable because the capacity of a society to use natural resources in an efficient manner is likely to increase with growing socio-economic status, which might have some impact upon the very technologies and systems that allow the society to utilize resources efficiently. In effect, as shown in Figs. 3 and 4, the scores of the resource component generally improved between 2000 and 2005, except for some provinces with a slight decrease in scores for the period.

We showed in this study that the aggregate sustainability index scores and rankings based upon the scores are useful in investigating the macro trends of the sustainability status of provinces. It should be noted, however, that the calculation results of scores could be influenced by the assessment framework, such as types of variables and weighting among variables and components in the process of aggregation. Thus, the ultimate interpretation of sustainability conditions of targeted regions always necessitates a multilateral analysis, along with results derived from the indicative assessment method that we have proposed.

\section{Conclusions}

After reviewing the representative assessment indicators, this paper proposed a novel sustainability assessment method designed to calculate aggregate sustainability 
Table 4 Scores by component: environment, resource, and socioeconomic (2000 and 2005)

\begin{tabular}{|c|c|c|c|c|c|}
\hline \multicolumn{3}{|c|}{ Econominc ( 2000 allu 2003$)$} & \multirow{2}{*}{\multicolumn{2}{|c|}{2000}} & \multirow{2}{*}{2005} \\
\hline & & & & & \\
\hline & 2000 & 2005 & Hubei & 0.42 & 0.51 \\
\hline \multicolumn{3}{|l|}{ Environment } & Hunan & 0.46 & 0.49 \\
\hline Beijing & 0.70 & 0.81 & Guangdong & 0.51 & 0.54 \\
\hline Tianjin & 0.77 & 0.67 & Guangxi & 0.44 & 0.52 \\
\hline Hebei & 0.26 & 0.17 & Hainan & 0.74 & 0.84 \\
\hline Shanxi & 0.35 & 0.25 & Chongqing & 0.60 & 0.65 \\
\hline Inner Mongolia & 0.51 & 0.33 & Sichuan & 0.52 & 0.65 \\
\hline Liaoning & 0.35 & 0.34 & Guizhou & 0.25 & 0.32 \\
\hline Jilin & 0.58 & 0.55 & Yunnan & 0.59 & 0.62 \\
\hline Heilongjiang & 0.54 & 0.53 & Tibet & 0.89 & 0.88 \\
\hline Shanghai & 0.51 & 0.56 & Shaanxi & 0.43 & 0.51 \\
\hline Jiangsu & 0.25 & 0.19 & Gansu & 0.15 & 0.33 \\
\hline Zhejiang & 0.59 & 0.56 & Qinghai & 0.57 & 0.34 \\
\hline Anhui & 0.50 & 0.45 & Ningxia & 0.23 & 0.34 \\
\hline Fujian & 0.68 & 0.67 & Xinjiang & 0.30 & 0.46 \\
\hline Jiangxi & 0.46 & 0.51 & & & \\
\hline Shandong & 0.21 & 0.17 & Mean value & 0.46 & 0.52 \\
\hline Henan & 0.33 & 0.24 & \multicolumn{3}{|l|}{ Socio-economic } \\
\hline Hubei & 0.36 & 0.33 & Beijing & 0.88 & 0.96 \\
\hline Hunan & 0.46 & 0.40 & Tianjin & 0.75 & 0.90 \\
\hline Guangdong & 0.49 & 0.43 & Hebei & 0.40 & 0.76 \\
\hline Guangxi & 0.45 & 0.32 & Shanxi & 0.35 & 0.60 \\
\hline Hainan & 0.87 & 0.81 & Inner Mongolia & 0.37 & 0.54 \\
\hline Chongqing & 0.52 & 0.53 & Liaoning & 0.69 & 0.84 \\
\hline Sichuan & 0.34 & 0.31 & Jilin & 0.52 & 0.67 \\
\hline Guizhou & 0.39 & 0.40 & Heilongjiang & 0.53 & 0.69 \\
\hline Yunnan & 0.64 & 0.60 & Shanghai & 0.92 & 0.98 \\
\hline Tibet & 0.87 & 0.97 & Jiangsu & 0.60 & 0.87 \\
\hline Shaanxi & 0.55 & 0.52 & Zhejiang & 0.68 & 0.92 \\
\hline Gansu & 0.56 & 0.51 & Anhui & 0.23 & 0.51 \\
\hline Qinghai & 0.71 & 0.52 & Fujian & 0.52 & 0.82 \\
\hline Ningxia & 0.69 & 0.64 & Jiangxi & 0.32 & 0.65 \\
\hline Xinjiang & 0.65 & 0.50 & Shandong & 0.45 & 0.61 \\
\hline \multirow[t]{2}{*}{ Mean value } & \multirow[t]{2}{*}{0.51} & \multirow[t]{2}{*}{0.46} & Henan & 0.31 & 0.56 \\
\hline & & & Hubei & 0.33 & 0.50 \\
\hline \multicolumn{3}{|l|}{ Resource } & Hunan & 0.33 & 0.65 \\
\hline Beijing & 0.79 & 0.77 & Guangdong & 0.62 & 0.86 \\
\hline Tianjin & 0.67 & 0.71 & Guangxi & 0.26 & 0.57 \\
\hline Hebei & 0.52 & 0.55 & Hainan & 0.42 & 0.61 \\
\hline Shanxi & 0.19 & 0.32 & Chongqing & 0.21 & 0.43 \\
\hline Inner Mongolia & 0.29 & 0.25 & Sichuan & 0.21 & 0.64 \\
\hline Liaoning & 0.25 & 0.38 & Guizhou & 0.07 & 0.21 \\
\hline Jilin & 0.31 & 0.34 & Yunnan & 0.11 & 0.21 \\
\hline Heilongjiang & 0.37 & 0.58 & Tibet & 0.04 & 0.03 \\
\hline Shanghai & 0.61 & 0.69 & Shaanxi & 0.22 & 0.54 \\
\hline Jiangsu & 0.58 & 0.64 & Gansu & 0.13 & 0.24 \\
\hline Zhejiang & 0.62 & 0.60 & Qinghai & 0.12 & 0.42 \\
\hline Anhui & 0.40 & 0.45 & Ningxia & 0.26 & 0.21 \\
\hline Fujian & 0.58 & 0.64 & Xinjiang & 0.29 & 0.66 \\
\hline Jiangxi & 0.27 & 0.31 & & & \\
\hline Shandong & 0.58 & 0.68 & Mean value & 0.40 & 0.60 \\
\hline Henan & 0.50 & 0.55 & & & \\
\hline
\end{tabular}

Table 4 continued 
Fig. 1 Environment component scores (2000)

Fig. 2 Environment component scores (2005)
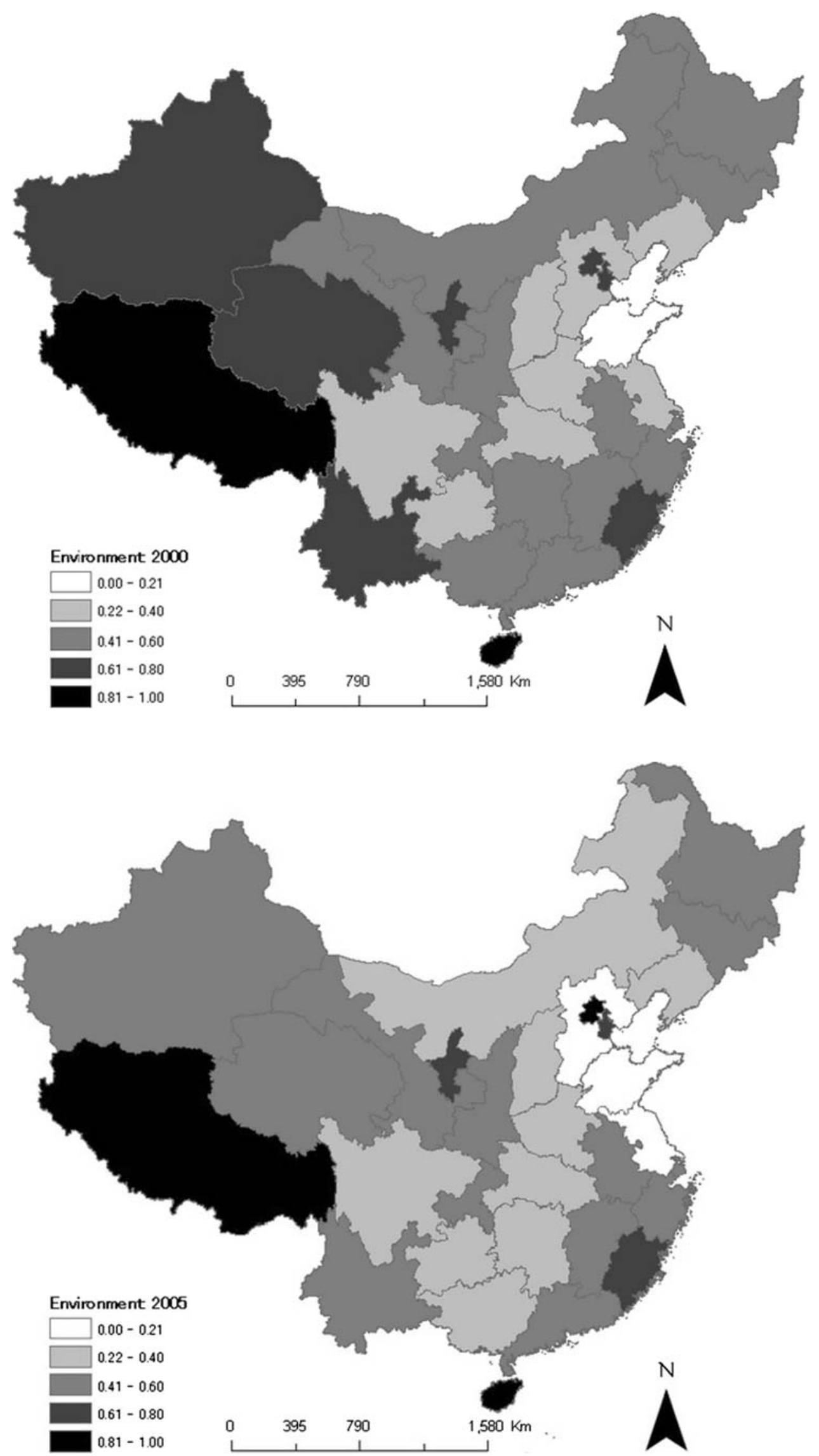
Fig. 3 Resource component scores (2000)

Fig. 4 Resource component scores (2005)
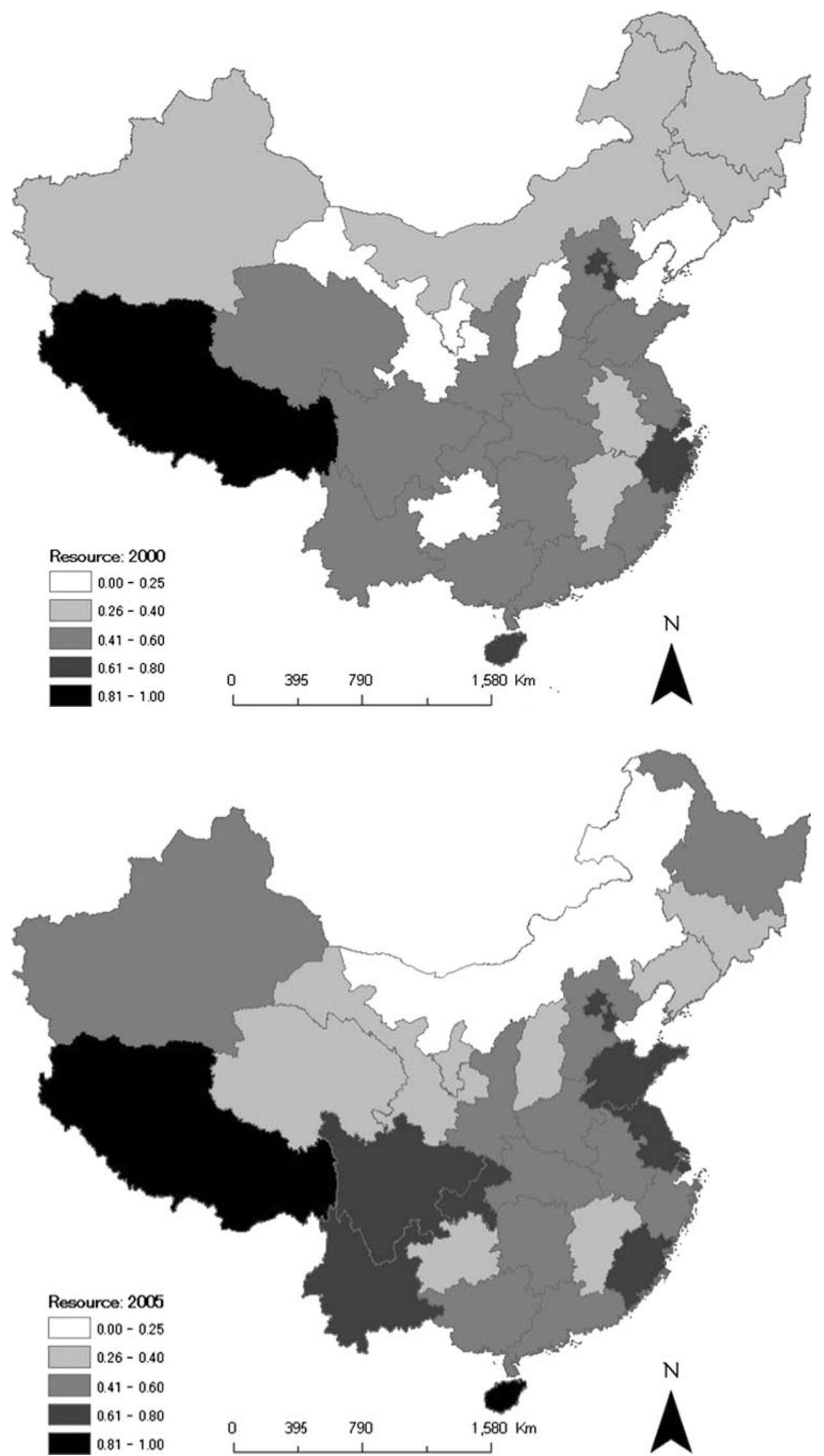
Fig. 5 Socio-economic component scores (2000)

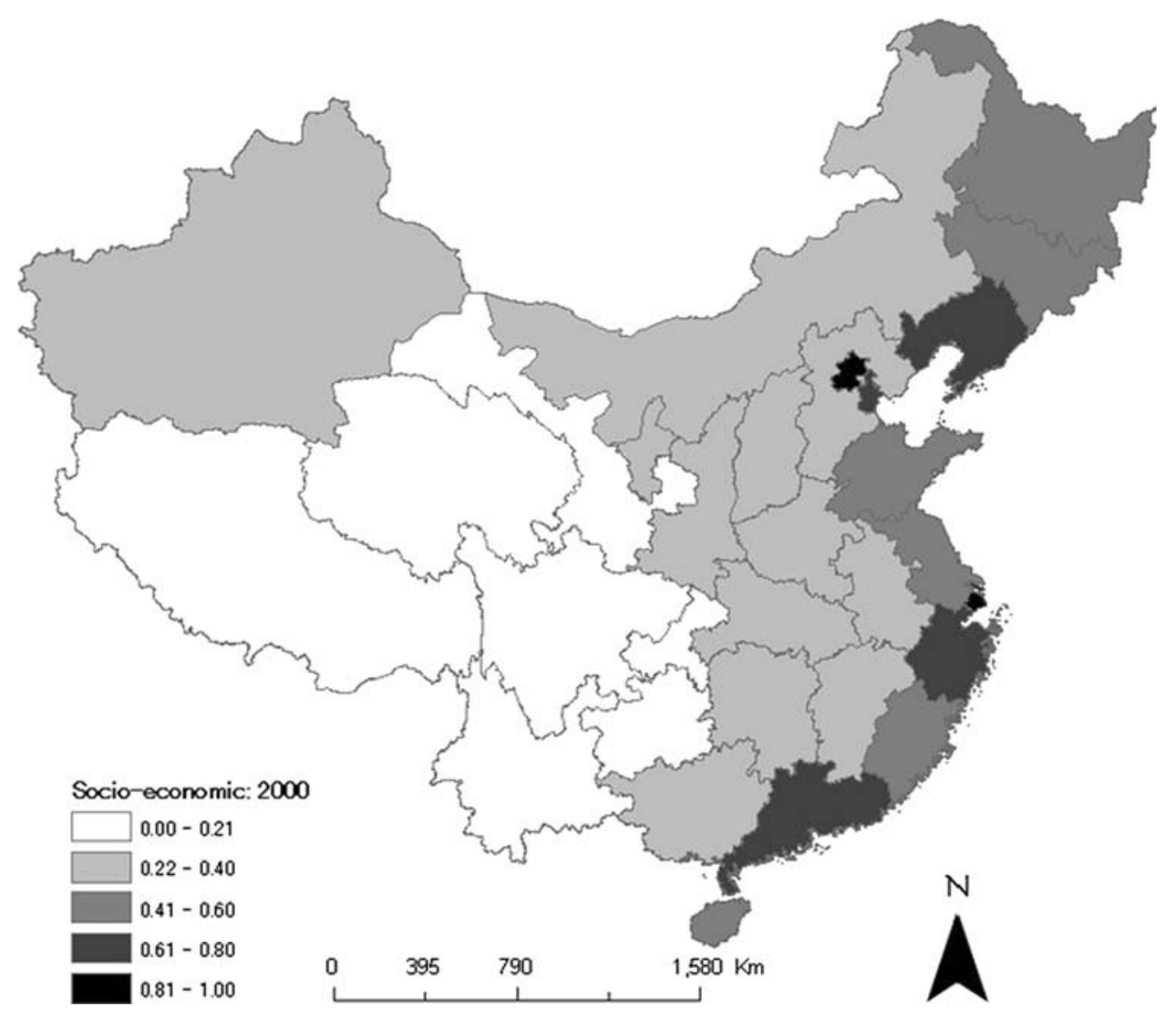

Fig. 6 Socio-economic component scores (2005)

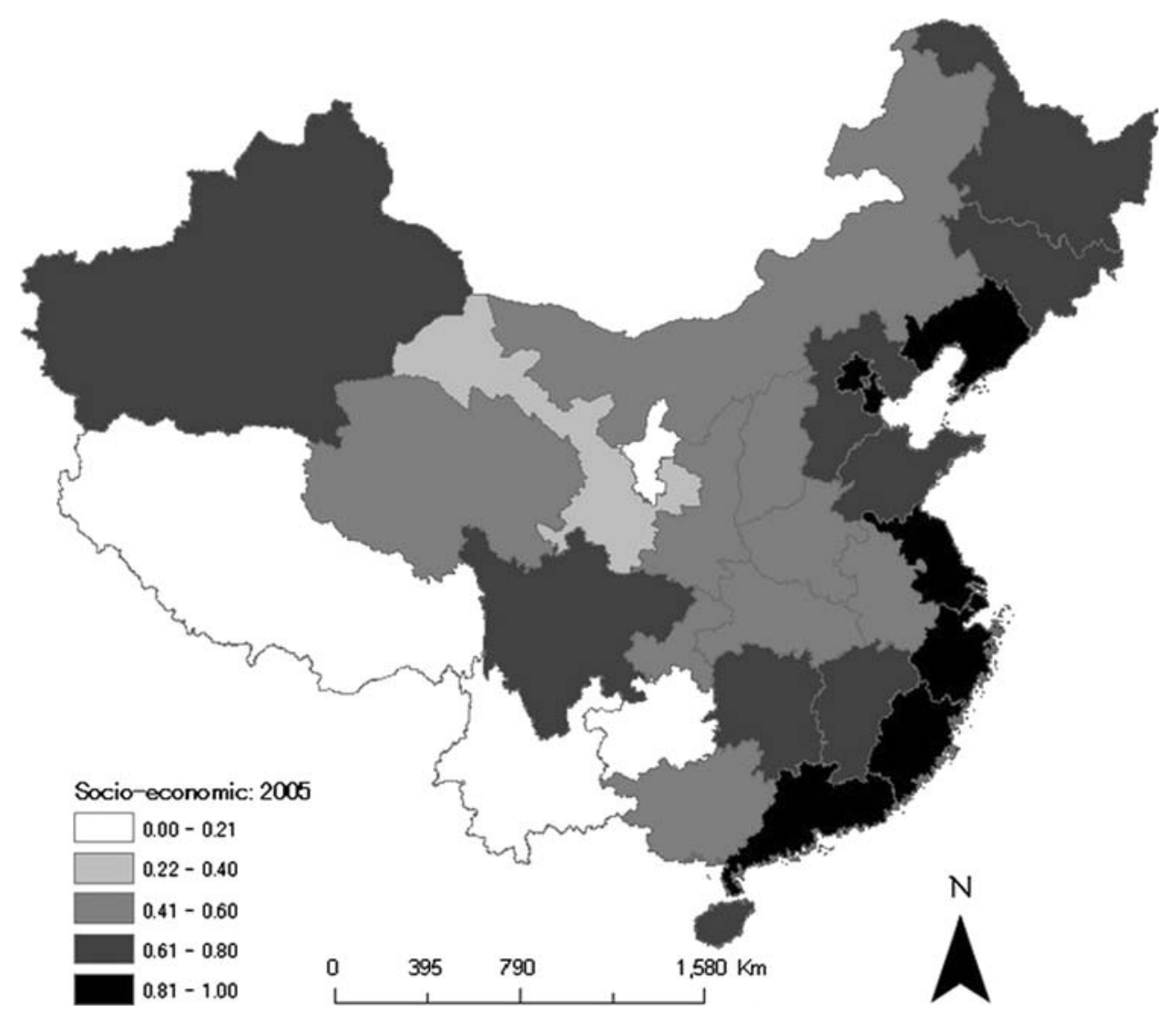


Fig. 7 Sustainability index scores (2000)

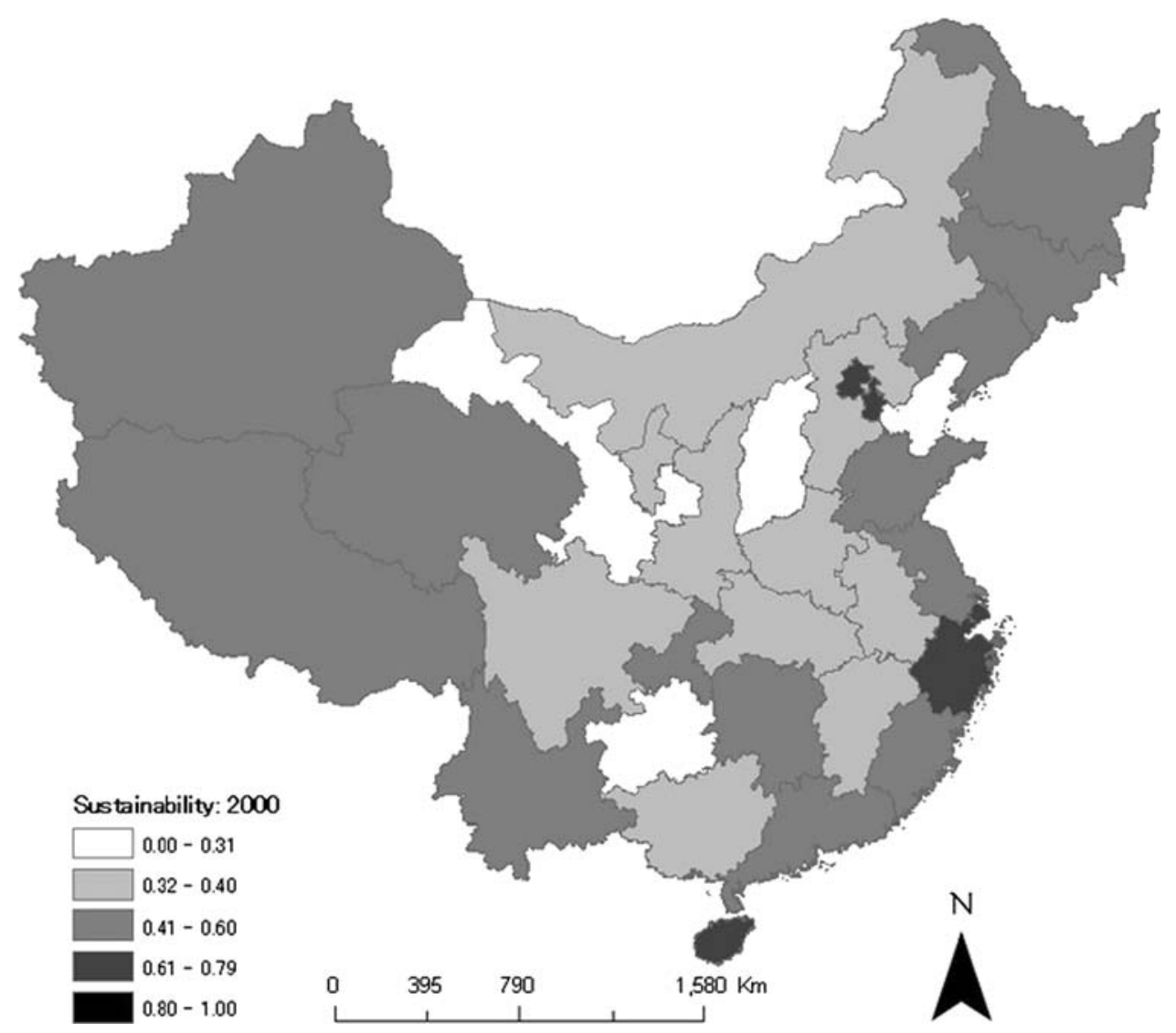

Fig. 8 Sustainability index scores (2005)

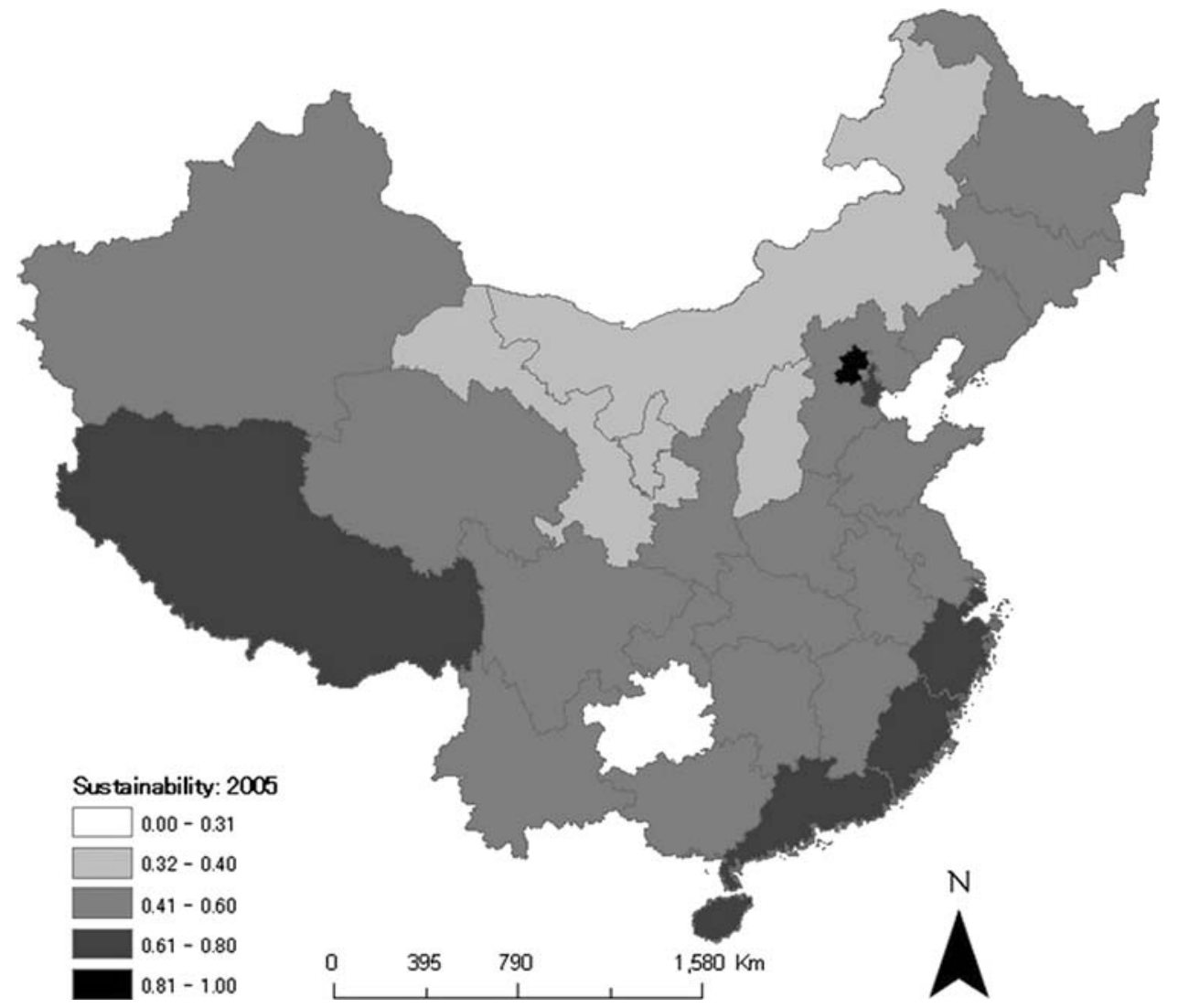




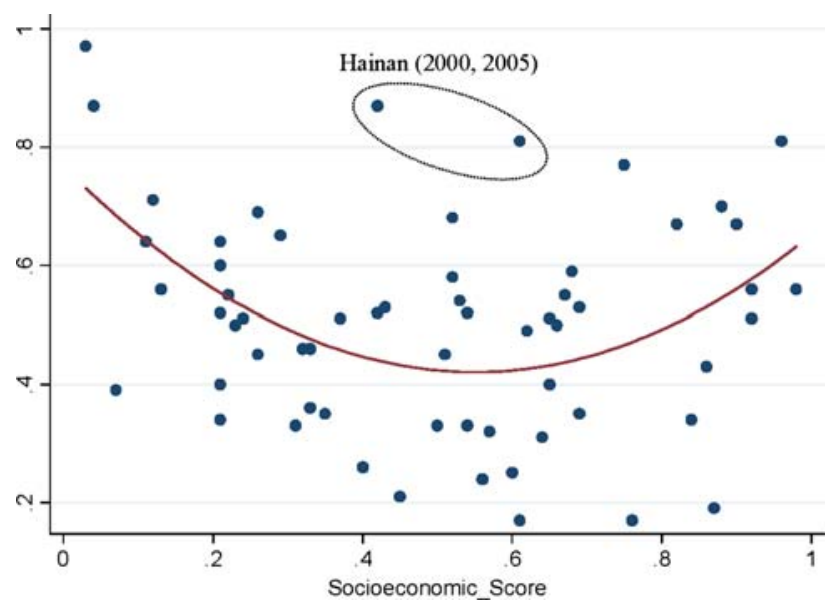

Fig. 9 Correlation between the scores of socio-economic and environment components

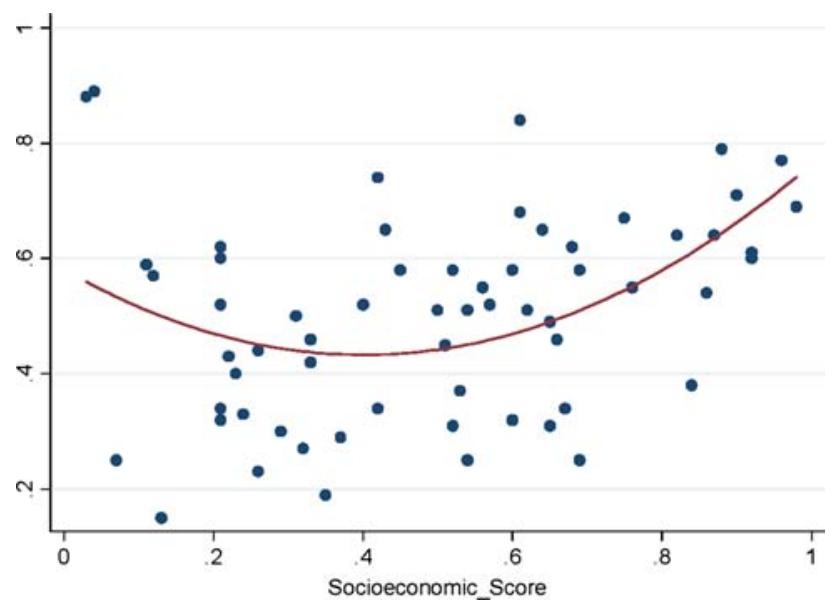

Fig. 10 Correlation between the scores of socio-economic and resource components

scores with three components for two different years, and the method was applied to evaluate the sustainability status of China's provinces. The method was found to be effective in analyzing the relative sustainability status across provinces for the different time periods. In addition to the aggregate sustainability index scores, the method simultaneously enabled the clarification of trends for individual variables, such as income gaps in the socioeconomic component, and investigation by three components, making it possible to undertake a comprehensive analysis.

The results clarified whether each province had been moving in a positive direction in terms of environmental status, efficient resource utilization, and socio-economic conditions, as represented in the examined three components, and sustainability status in an integrated manner, along with the examination of individual variables. The results also demonstrated the rankings of sustainability among provinces for the different time periods. Such information derived from the method shall be useful for obtaining the pictures of relative or indicative sustainability status and understanding of good performances or potential problems in individual provinces from sustainability perspectives and, therefore, could be of help especially in the initial stage of policy analysis and decision-making processes for guiding society to a sustainable future, although the results are necessarily affected by the credibility and availability of the primary data.

In conclusion, the proposed method proved to be useful in the following senses. First, it is capable of determining the relative sustainability status of targeted regions for different time periods on a common basis, in the form of aggregate scores. Thus, the results could clarify which regions performed well or poorly from the viewpoint of sustainability, as well as the changes in performances over time. These findings could serve as basic data for the macro-analysis of indicative sustainability performance. Second, information was provided from the decomposed elements of sustainability, that is, environment, resource, and socio-economic components in this study. Therefore, detailed and micro-level analysis of individual variables and investigation by components are also possible.

In the present study, which shall serve as a prototype, we selected three components and 22 variables under the components and applied equal weighting for aggregation as an exercise for this Chinese case study. The results are subject to the framework and selection of variables, as well as the data availability for such variables. In future studies, modifications or additions of variables and different weighting ratios among variables and components, which could be dynamic in accordance with local conditions and backgrounds, shall be examined in order to develop the most appropriate assessment method.

Acknowledgments This work was supported by the Ministry of Education, Culture, Sports, Science and Technology (MEXT) of Japan through Special Coordination Funds for Promoting Science and Technology, as part of the flagship research project "Development of an Asian Recycling-Oriented Society."

\section{Appendix}

The actual $z$-scores of the resource component are shown in Table 5. 
Table 5 Calculated $z$-scores of variables under the resources component (2000 and 2005)

\begin{tabular}{|c|c|c|c|c|c|c|c|c|c|c|c|c|}
\hline & \multicolumn{4}{|l|}{ Energy } & \multicolumn{6}{|l|}{ Water } & \multirow{2}{*}{\multicolumn{2}{|c|}{$\frac{\text { Waste/material }}{\text { Solid waste utilization }}$}} \\
\hline & \multicolumn{2}{|c|}{ Fuel oil/GRP } & \multicolumn{2}{|c|}{ Coal/GRP } & \multicolumn{2}{|c|}{ Industrial water/GRP } & \multicolumn{2}{|c|}{ Water supply/GRP } & \multicolumn{2}{|c|}{ Water availability/capita } & & \\
\hline & 2000 & 2005 & 2000 & 2005 & 2000 & 2005 & 2000 & 2005 & 2000 & 2005 & 2000 & 2005 \\
\hline Beijing & -0.90 & -0.49 & 0.78 & 1.17 & 0.44 & 0.66 & 1.84 & 1.26 & 1.74 & 1.28 & 0.83 & 0.65 \\
\hline Tianjin & -0.90 & 0.04 & 0.38 & 0.27 & -0.29 & -0.34 & 0.41 & 0.29 & 1.74 & 1.74 & 1.27 & 1.23 \\
\hline Hebei & 0.04 & 0.04 & -0.42 & -0.47 & -0.38 & -0.63 & 0.16 & 0.90 & 1.28 & 1.28 & -0.33 & -0.38 \\
\hline Shanxi & 0.04 & 1.32 & -2.86 & -2.79 & -1.67 & -1.59 & -0.54 & -0.32 & 0.82 & 1.01 & -1.13 & -0.41 \\
\hline Inner Mongolia & 1.32 & 0.04 & -1.14 & -1.82 & -1.35 & -1.06 & -0.21 & 0.09 & -0.27 & -0.20 & -1.62 & -1.11 \\
\hline Liaoning & -2.07 & -0.90 & -0.35 & -0.08 & -0.41 & -0.03 & -1.14 & -0.56 & 0.68 & 0.29 & -0.74 & -0.62 \\
\hline Jilin & -0.90 & 0.04 & -0.31 & -0.22 & -0.08 & -0.35 & -1.75 & -1.62 & 0.10 & -0.27 & 0.01 & -0.05 \\
\hline Heilongjiang & -0.90 & 0.04 & -0.28 & -0.08 & -0.45 & 0.12 & -0.65 & 0.65 & -0.30 & -0.20 & 0.52 & 0.71 \\
\hline Shanghai & -1.24 & -0.49 & 0.55 & 0.73 & -0.46 & 0.15 & -0.53 & -0.44 & 1.74 & 1.74 & 1.54 & 1.23 \\
\hline Jiangsu & -0.49 & -0.49 & 0.35 & 0.30 & -0.01 & 0.39 & -0.10 & 0.22 & 0.37 & 0.56 & 1.08 & 1.12 \\
\hline Zhejiang & -0.49 & -0.49 & 0.62 & 0.66 & 0.29 & 0.36 & 0.44 & 0.28 & 0.10 & -0.27 & 0.91 & 1.02 \\
\hline Anhui & 0.04 & 0.04 & 0.00 & -0.02 & -0.58 & -0.37 & -1.42 & -1.25 & -0.13 & 0.10 & 0.66 & 0.78 \\
\hline Fujian & -0.49 & 0.04 & 1.15 & 0.80 & 1.13 & 0.86 & 0.18 & 0.73 & -0.33 & -0.70 & -0.40 & 0.44 \\
\hline Jiangxi & 0.04 & 0.04 & 0.16 & 0.07 & 0.33 & 0.07 & -1.08 & -0.99 & -0.55 & -0.61 & -2.61 & -1.56 \\
\hline Shandong & -0.90 & 0.04 & 0.11 & 0.08 & 0.08 & 0.15 & 0.44 & 0.69 & 0.68 & 0.82 & 0.82 & 1.04 \\
\hline Henan & 0.04 & 0.04 & -0.30 & -0.27 & -0.56 & -0.43 & -0.06 & 0.42 & 0.45 & 0.56 & 0.39 & 0.42 \\
\hline Hubei & 0.04 & 0.04 & 0.14 & 0.18 & -0.02 & 0.22 & -1.52 & -0.79 & -0.27 & -0.09 & 0.39 & 0.61 \\
\hline Hunan & 0.04 & 0.04 & 0.30 & 0.34 & 0.72 & 0.60 & -1.64 & -1.16 & -0.44 & -0.41 & 0.34 & 0.44 \\
\hline Guangdong & -2.30 & -1.82 & 1.10 & 1.12 & 0.67 & 0.88 & 0.34 & -0.17 & -0.17 & -0.20 & 0.50 & 0.83 \\
\hline Guangxi & 0.04 & 1.32 & 0.04 & 0.09 & 0.56 & -0.06 & -0.90 & -0.54 & -0.68 & -0.64 & 0.06 & 0.20 \\
\hline Hainan & 0.04 & 1.32 & 1.37 & 1.51 & 1.75 & 1.58 & 1.26 & 1.73 & -0.63 & -0.64 & 0.10 & 0.43 \\
\hline Chongqing & 1.32 & 1.32 & -0.10 & 0.38 & -0.58 & -0.34 & 0.48 & 0.51 & -0.20 & -0.17 & 0.58 & 0.57 \\
\hline Sichuan & 1.32 & 1.32 & 0.02 & 0.23 & 0.53 & 0.44 & -0.63 & 0.76 & -0.51 & -0.63 & -0.43 & 0.16 \\
\hline Guizhou & 0.04 & -0.49 & -1.37 & -1.27 & -1.18 & -1.14 & 0.08 & 0.95 & -0.36 & -0.30 & -1.19 & -0.60 \\
\hline Yunnan & 1.32 & 1.32 & -0.52 & -0.54 & 0.29 & 0.26 & 1.54 & 2.06 & -0.68 & -0.71 & -0.52 & -0.61 \\
\hline Tibet & 1.32 & 1.32 & 2.68 & 2.78 & 3.19 & 3.27 & 2.10 & 1.67 & -3.19 & -3.13 & - & - \\
\hline Shaanxi & 1.32 & 1.32 & -0.36 & -0.39 & -0.21 & -0.01 & 0.58 & 1.05 & -0.09 & 0.05 & -2.34 & -1.88 \\
\hline Gansu & -1.82 & 0.04 & -0.41 & -0.56 & -0.97 & -0.77 & -1.79 & -0.60 & 0.29 & 0.22 & -1.62 & -1.04 \\
\hline Qinghai & 0.04 & 1.32 & 0.11 & -0.19 & 0.81 & 0.23 & -0.56 & -0.08 & -1.42 & -1.62 & 2.06 & -2.05 \\
\hline Ningxia & 0.04 & 1.32 & -1.62 & -1.97 & -2.49 & -2.43 & -1.39 & -1.07 & 1.28 & 1.74 & -0.24 & -0.07 \\
\hline Xinjiang & -2.92 & -0.49 & 0.18 & -0.08 & 0.15 & 0.06 & 0.52 & 0.87 & -0.82 & -0.82 & -0.19 & -0.22 \\
\hline
\end{tabular}

\section{References}

Butler D, Parkinson J (1997) Towards sustainable urban drainage. Water Sci Technol 35(9):53-63

Costanza R, d'Arge R, de Groot R, Farber S, Grasso M, Hannon B, Limburg K, Naeem S, O’Neill RV, Paruelo J, Raskin RG, Sutton P, van den Belt M (1997) The value of the world's ecosystem services and natural capital. Nature 387:253-260

Daly H (1991) Elements of environmental macroeconomics. In: Costanza R (ed) Ecological economics. The science and management of sustainability. Columbia University Press, New York, pp 32-46

Dudek D, Zhong M, Zhang J, Song G, Liu S (2001) Total emission control of major pollutants in China. China Environment Series. Woodrow Wilson International Center for Scholars, Washington, DC
Ehrlich PR, Ehrlich AH (2008) Nature's economy and the human economy. Environ Resour Econ 39:9-16

Ekins S, Dresner S, Dahlstrom K (2008) The four-capital method of sustainable development evaluation. Eur Environ 18:63-80

Esty D, Levy M, Srebotnjak T (2005) 2005 environmental sustainability index: benchmarking national environmental stewardship. Yale Center for Environmental Law and Policy, New Haven

Feng Z, Yan N (2007) Putting a circular economy into practice in China. Sustain Sci 2(1):95-101

Hardi P, Zdan T (eds) (1997) Assessing sustainable development: principles in practice. International Institute for Sustainable Development, Winnipeg, Canada

Hellström D, Jeppsson U, Kärrman E (2000) A framework for systems analysis of sustainable urban water management. Environ Impact Assess Rev 20:311-321 
International Union for the Conservation of Nature (1991) Caring for the Earth: a strategy for sustainable living. Earthscan Publications, London

Lundin M, Molander S, Morrison GM (1999) A set of indicators for the assessment of temporal variations in the sustainability of sanitary system. Water Sci Technol 39(5):235-242

Mels AR, van Nieuwenhuijzen AF, van der Graaf JHJM, Klapwijk B, de Koning J, Rulkens WH (1999) Sustainability criteria as a tool in the development of new sewage treatment methods. Water Sci Technol 39(5):243-250

Ministry of the Environment (MOE) (2003) Fundamental plan for establishing a sound material-cycle society. MOE, Tokyo

National Bureau of Statistics (2000) China statistical yearbook. China Statistics Press, Beijing

National Bureau of Statistics (2001) China statistical yearbook. China Statistics Press, Beijing

National Bureau of Statistics (2002) China statistical yearbook. China Statistics Press, Beijing

National Bureau of Statistics (2004) China statistical yearbook. China Statistics Press, Beijing

National Bureau of Statistics (2005) China statistical yearbook. China Statistics Press, Beijing

National Bureau of Statistics (2006) China statistical yearbook. China Statistics Press, Beijing

Ness B, Urbel-Piirsalu E, Anderberg S, Olsson L (2007) Categorizing tools for sustainability assessment. Ecol Econ 60(3):498-508

Organisation for Economic Co-operation and Development (OECD) (1993) Core set of indicators for environmental performance reviews. OECD, Paris

Organisation for Economic Co-operation and Development (OECD) (2000) Towards sustainable development: indicators to measure progress. Proceedings of the Rome Conference. OECD, Paris

Organization for Economic Cooperation and Development (2001) The well-being of nations: the role of human and social capital. OECD, Paris

Organisation for Economic Cooperation Development (2003) OECD environmental indicators: development, measurement and use. Reference Paper, OECD, Paris
Robert KH (2002) The natural step story: seeding a quiet revolution. New Society Publishers, Canada

State Environmental Protection Administration (SEPA) (2001) The national tenth five-year plan for environmental protection, no. 76. SEPA, Beijing (in Chinese)

Sustainable Seattle (1998) Indicators of sustainable community. Seattle, Washington

United Nations Commission on Sustainable Development (UNCSD) (2001) Indicators of sustainable development: guidelines and methodologies. UNCSD

United Nations Development Program (UNDP) (2006) Human Development Report 2006. Beyond scarcity: power, poverty and the global water crisis. UNDP, New York

Wackernagel M, Rees WE (1996) Our ecological footprint: reducing human impact on the earth. New Society Publishers, Gabriola Island, Canada

Wackernagel M, Moran D, White S, Murray M (2006) Ecological footprint accounts for advancing sustainability: measuring human demands on nature. In: Lawn $P$ (ed) Sustainable development indicators in ecological economics. Edward Elgar, Cheltenham

World Bank (2006) Where is the wealth of nations? Measuring capital for the 21st century. The International Bank for Reconstruction and Development/The World Bank, Washington, DC

World Commission on Environment and Development (WCED) (1987) Our common future. Oxford University Press, UK

World Wildlife Federation (WWF) (2006) Living Planet Report 2006. WWF International, Institute of Zoology and Global Footprint Network, Gland, Switzerland

Yabar H, Hara K, Uwasu M, Yamaguchi Y, Zhang H, Morioka T (2009) Integrated resource management towards a sustainable Asia: policy and strategy evolution in Japan and China. Int $\mathbf{J}$ Environ Technol Manage (in press) 